\title{
Two-sector disequilibrium growth
}

\author{
Charles van Marrewijk ${ }^{a, b} *$, Jos Verbeek ${ }^{b, c}$ \\ ${ }^{2}$ Department of International Economics H8-13, Erasmus University Rotterdam, P.O. Box 1738, \\ 3000 DR Rotterdam, The Netherlands \\ ${ }^{\mathrm{b}}$ Tinbergen Institute, Erasmus University Rotterdam, P.O. Box 1738, 3000 DR Rotterdam, \\ The Netherlands \\ ' World Bank, Washington DC, USA
}

Accepted for publication February 1993

\begin{abstract}
We investigate the effects of (i) profit distribution to either laborers or capital-owners, (ii) sector-specific or efficient rationing schemes, and (iii) government consumption in a two-sector disequilibrium growth model with sluggish real wage rate adjustment (which affects capital accumulation).
\end{abstract}

Key words: Investment; Rationing; Unemployment; Excess demand

JEL classification: $\mathrm{C} 6 ; \mathrm{E} 2 ; \mathrm{E} 3 ; \mathrm{H} 3$

\section{Introduction}

Two different strands of economic literature have recently received widespread attention: growth theory and neo-Keynesian disequilibrium econ-

\footnotetext{
* Corresponding author. We would like to thank, without implicating, seminar participants at the Universities of Amsterdam, Antwerp, Eindhoven, Maryland, Montreal and Rotlerdam as well as two anonymous referees, Peter van Bergeijk, Andries Brandsma, Russel Cooper, Pierre Dehez, Eric Drissen, Martijn Herrmann, Sheng Cheng Hu, Edmund Malinvaud, Marcel Peeters, Rick van der Ploeg, Jean-Marie Viaene, Casper de Vries and especially Claus Weddepohl for their useful suggestions and perceptive comments. Jeroen Hinloopen provided able graphical assistance. An earlier version was presented at the Econometric Society European Meeting, Cambridge 1991. This paper is part of a larger study on disequilibrium growth theory (involving a.o. international repercussions and sector-specific capital) and was partly written while the authors were visiting scholars at Cornell University. Financial support from the Erasmus University Trust Fund and the Netherlands Scientific Organization is gratefully acknowledged. The views expressed in the paper are those of the authors and not necessarily those of the World Bank.
} 
omics. This attention, aimed at solving some shortcomings of the existing literature, is applaudable as growth effects are ultimately more important than level effects and the ubiquitous nature of market disequilibrium is almost undisputed. However, the recent contributions fail to integrate the two approaches or to address two problems in particular. First, the NeoKeynesian theories of market disequilibrium are static in nature because they lack an endogenous capital accumulation process (which in general will influence the type of short-run equilibrium studied in these models). This holds not only for the 'old' Neo-Keynesian literature but also for the 'NeoNeo' (or New) Keynesians. ${ }^{1}$ Second, growth theory analyzes the impact of (human) capital accumulation over time, but fails to analyze the consequences of market disequilibrium. Again this holds both for the 'old' growth theory and for the 'new' (endogenous) growth theory. ${ }^{2}$ Disequilibrium growth theory, introduced by Ito (1980), overcomes the static nature of disequilibrium economics and the equilibrium nature of growth theory and integrates the two approaches by simultaneously studying both short-run market disequilibrium and endogenous capital accumulation over time that will affect the short-run equilibrium.

A technical problem arises in the theory of disequilibrium growth as the possibility of switches in the short-run disequilibrium regime, say from unemployment to excess demand, gives rise to a discontinuity in the investment scheme. This, in turn, implies that the differential equations describing the dynamic evolution of the economy have discontinuous right hand sides. Following Ito (1980), and others, we employ the Filippov (1960) solution concept, which generalizes the theory of ordinary differential cquations and allows us to cope with discontinuities and multivaluedness of the vector field.

Since its introduction by Ito disequilibrium growth theory has not received the attention it deserves. ${ }^{3}$ Honkapohja and Ito (1983) and Eckwert and Schittko (1988) give further developments of the Filippov technique. Honkapohja and Ito (1982), Picard (1983) and Schittko and Eckwert (1985) investigate monetary versions of the neo-Keynesian model. Ginsburgh et al. (1985) study endogenous savings behavior in a Ramsey framework. Finally, van Marrewijk and Verbeek (1993a) study a two-sector model in a small open economy and van Marrewijk and Verbeek (1993b) investigate the implications of sector-specific capital.

\footnotetext{
${ }^{1}$ See Barro and Grossman (1971) or Benassy (1982), respectively Cooper and John (1988). Space limitations prompt us to list a few references only. A more extended list can be found in Verbeek (1993).

${ }^{2}$ See Solow (1956) respectively Romer (1986).

${ }^{3}$ This is partly caused by the technical dynamic problems alluded to above.
} 
This article differs from existing disequilibrium growth theory in four respects (discussed sequentially in the rest of the paper). First, we extend the Ito (1980) model, which analyzes unemployment or excess-demand on the labor market, to two sectors, by recognizing the fact that consumption goods and investment goods are inherently different commodities, produced in two distinct sectors of the economy by employing capital and labor as inputs. Second, we investigate the effects of profit distribution to either the laborers or capital-owners on the disequilibrium growth path. Third, the introduction of a second sector enables us to analyze different rationing schemes, namely efficient rationing or rationing either the investment good sector or the consumption good sector. Fourth, we briefly investigate the impact of government consumption on the short-run and long-run behavior of the economy.

The source of short-run disequilibrium in our model will be sluggish real wage rate adjustment. Numerous theories have been put forward to explain real or nominal stickiness. Blinder (1991), for example, recently reported about ongoing research (using interview studies) on 12 theories of sluggish adjustment. His preliminary conclusion is that adjustment is indeed sluggish: the mean response lag between a change in demand or cost and an adjustment is 3 to 4 months and less than $15 \%$ of GNP is repriced more frequently than quarterly. The production functions in the two sectors of the economy, the consumption good sector and the investment good sector, are characterized by constant returns to scale, which enables the model to be written in per capita form. We retain the Solow (1956) assumption of fixed savings rates, but allow for these rates to be different for capital-owners and laborers.

If there is excess-demand for labor in a one-sector disequilibrium growth model the rationing scheme used to allocate the available supply of laborers is trivial as there is only one sector to be rationed. Analyzing a two-sector disequilibrium growth model necessarily entails the introduction of a nontrivial rationing scheme to distribute the available supply of labor over the two sectors if the demand for labor is rationed. First, we will investigate an efficient rationing scheme that has the two basic properties, voluntary exchange and market efficiency, stressed in the literature, see e.g. Benassy (1982). More specifically, it is assumed that the short side rule holds and that in the excess-demand regime labor will be allocated to the two sectors so as to equalize the value marginal product of labour. As a result of efficient rationing the profits per worker, and hence the marginal incentive for a producer to employ a worker in his company, will be equal in the two sectors. Second, we investigate priority rationing, see e.g. Benassy (1982, p. 128) or Picard (1983, p. 275). Sometimes a particular agent (usually the government) gets priority. Alternatively, a specific sector of the economy can get priority, perhaps because it is designated to be of 'strategic interest' by 
the government. For example, the investment good industry is allowed, at the current below-equilibrium wage rate, to employ as many laborers as it wants, such that the labor shortage shows up exclusively in the consumption goods sector.

The results derived in this paper will be stated precisely and have been proven formally, but will be discussed tersely and informally. Detailed proofs of the short-term existence propositions and the results on efficient rationing can be found in Verbeek (1993), while details on sector-specific rationing are available from the authors upon request.

\section{The model}

\subsection{Full employment}

Sector 1, the numéraire, produces investment goods, $Y_{1}$, while sector 2 (with relative price $p$ ) produces consumption goods, $Y_{2}{ }^{4}$ Both sectors produce under constant returns to scale and use labor, $L$, and capital, $K$, as inputs. The intensive form of the production functions $\left(f_{i}\left(k_{i}\right), i=1,2\right)$ is well-behaved and satisfies the Inada conditions. ${ }^{5}$ Laborers (capital-owners) save a fraction $s_{w}\left(s_{r}\right)$ out of their income, with $0 \leqslant S_{w}, S_{r} \leqslant 1$. Firms in each sector maximize profits taking prices, the wage rate, $w$, and the rental rate, $r$, as given. Because of perfect capital and labor mobility between the two sectors both factors of production will be fully used and the rental rate and the wage rate are the same in both sectors. If the firms are on their demand curves for labor and capital, the wage rate and the rental rate will be equal to the value marginal product of labor ( $V M P L)$ and capital, respectively. Hence, if $\omega_{i}$ is the ratio of marginal productivities in sector $i, \omega_{i}\left(k_{i}\right)=$ $\left(f_{i} / f_{i}^{\prime}\right)-k_{i}$ for $i=1,2$, then $\omega_{1}=\omega_{2}=\omega$, say. Note that $\omega_{i}^{\prime}=-f_{i} f_{i}^{\prime \prime} /\left(f_{i}^{\prime}\right)^{2} \equiv \epsilon_{i}>$ 0 and that the sectorial elasticities of substitution $\sigma_{i}$ are given by $\sigma_{i}=\omega_{i} /\left(k_{i} \epsilon_{i}\right)$. The short-run full employment model as discussed above becomes

$$
\begin{aligned}
& y_{i}=l_{i} f_{i}\left(k_{i}\right), \quad i=1,2, \\
& y_{1}=s_{r} r k+s_{w} w, \\
& w=f_{1}-k_{1} f_{1}^{\prime}=p\left\{f_{2}-k_{2} f_{2}^{\prime}\right\}, \\
& r=f_{1}^{\prime}=p f_{2}^{\prime},
\end{aligned}
$$

\footnotetext{
${ }^{4}$ The choice of numeraire is immaterial for the static properties of the model, the local propositions below or efficient rationing if laborers receive the profits, but might affect Propositions 3 and 4(ii). We are grateful to an anonymous referee for pointing this out.

${ }^{5}$ All lower case variables are per-capita, except $k_{i}$ which equals $K_{i} / L_{i}$ and price variables, $p, r$ and $w$.
} 


$$
\begin{aligned}
& l_{1}+l_{2}=1, \\
& k=k_{1} l_{1}+k_{2} l_{2}, \\
& \omega=\left(f_{i} / f_{i}^{\prime}\right)-k_{i}, \quad i=1,2 .
\end{aligned}
$$

It is well known, see Drandakis (1963), that the short-run full employment equilibrium exists and is unique if $\sigma_{1}+\sigma_{\mathrm{s}} \geqslant 1$. Moreover, the wage rate that guarantees full employment, call it $w^{*}(k)$, is a rising function of $k$. In the long run the capital-labor ratio changes because agents save part of their income and invest this in new investment goods. Labor is supplied perfectly inelastically and grows exponentially at rate $n$. The capital accumulation equation can then be written as

$$
\dot{k}=y_{1}-(\delta+n) k
$$

where a dot above a variable denotes the first derivative with respect to time and $\delta$ is the non-negative depreciation rate. Let $\sigma_{F} \equiv(\omega / k)(\mathrm{d} k / \mathrm{d} \omega)$ be the economy-wide elasticity of substitution in the full employment regime. Several sufficient conditions for existence, uniqueness and stability of a longrun steady state $\hat{k}$, with concomitant $\hat{w}=w^{*}(\hat{k})$, are known. We will use $\sigma_{F} \geqslant 1$, which holds if $\sigma_{1}, \sigma_{2} \geqslant 1$.

\subsection{Disequilibrium}

In the full employment regime the wage rate adjusts instantly to pressure in the labor market to clear this market. Now, we introduce sluggish real wage rate adjustment such that there may be unemployment or excessdemand in the labor market. The short-run wage rate is then exogenously given. The actual quantity traded is determined by the short side rule, $L=\min \left\{L^{\mathrm{d}}, L^{\mathrm{s}}\right\}$, where $L^{\mathrm{d}}$ is the quantity of labor demanded and $L^{\mathrm{s}}$ the quantity supplied. We distinguish between the unemployment regime $\left(U ; L^{\mathrm{d}}<L^{\mathrm{s}}\right)$ and the excess-demand regime $\left(E ; L^{\mathrm{d}}>L^{\mathrm{s}}\right)$. The full employment regime, analyzed above, is the boundary between the two regimes. The regimes are described by the two state variables $k$ and $w$. It is the exogeneity of $w$, that causes the possibility of disequilibrium in the labor market. The analysis of the unemployment regime and the excess-demand regime has to distinguish between per capita variables obtained by dividing by the amount of labor demanded (indicated by a superscript d) on the one hand and per capita variables obtained by dividing by the amount of labor supplied on the other hand. Define $y_{i}^{\mathrm{d}} \equiv Y_{i} / L^{\mathrm{d}}, k_{i}^{\mathrm{d}} \equiv K_{i} / L_{i}^{\mathrm{d}}, l_{i}^{\mathrm{d}} \equiv L_{i}^{\mathrm{d}} / L^{\mathrm{d}}, k_{i} \equiv K_{i} / L_{i}^{\mathrm{s}}, l_{i} \equiv L_{i}^{\mathrm{s}} / L^{\mathrm{s}}$. The adjustment equation for the wage rate assumes, as usual, that the wage rate reacts to pressure in the labor market, i.e. 


$$
\dot{w}=\zeta_{j}\left\{\frac{k}{k^{d}}-1\right\} \equiv \theta_{j}(k, w) \text { for } j=E, U ; \zeta_{j}>0
$$

Note that we allow for different adjustment parameters $\left(\zeta_{i}\right)$ in the two regimes, i.e. the downward adjustment of wages in unemployment may be slow, while the upward adjustment of wages in excess demand may be fast.

\subsubsection{Unemployment}

In the unemployment regime the wage rate is too high, $w>w^{*}(k)$, to offer everyone a job, i.e. $L^{\mathrm{d}}<L^{\mathrm{s}}$. The producers are on their demand curve for labor, employing people up to the point where the VMPL equals the wage rate. Wages determine the amount of labor hired and the demanded capitallabor ratio $\left(k^{\mathrm{d}}=k^{\mathrm{d}}(w)=w^{*}(w)\right)$. Analysis of the unemployment regime is straightforward because we only have to substitute $y_{i}^{\mathrm{d}}, l_{i}^{\mathrm{d}}, k_{i}^{\mathrm{d}}$ and $k^{\mathrm{d}}$ for $y_{i}, l_{i}$, $k_{i}$ and $k$ respectively in Eqs. (1)-(7). Hence the following proposition follows easily, see also Ito $(1980)^{6}$.

Proposition 1. The short-run unemployment equilibrium exists and is unique. The state variables evolve according to $w<0$ and $\dot{k} \leqq 0$ iff $w \lesseqgtr \hat{w}$, provided $\sigma_{F} \geqslant 1$.

\subsubsection{Excess-demand}

In the excess-demand regime, $w<w^{*}(k)$, two things are important. First, profits are made as the wage rate deviates from the VMPL. These profits can go either to the laborers or to the capital-owners. Second, the type of rationing scheme of labor over the two sectors matters as the demand for labor exceeds the available supply. We will investigate three different rationing schemes: (i) efficient rationing, equalizing the $V M P L$ in both sectors, (ii) rationing of the consumption good sector, and (iii) rationing of the investment good sector. Therefore we need to rewrite the gross investment equation (2):

$$
y_{1}=s_{r} r k+s_{w} w+s_{\pi}\left(V M P L_{\pi}-w\right) l_{\pi}
$$

where, as will be explained below, $s_{n}=s_{m} s_{w} ; V M P L_{\pi}$ is the value marginal product of labor in the profit making sector(s); and $l_{\pi}$ is the fraction of labor employed in the profit making sector(s). As the static and dynamic properties of the model crucially hinge upon the rationing scheme and profit distribu-

\footnotetext{
${ }^{6}$ More specifically, in full employment capital accumulates according to $k=\phi(k) k$, for some function $\phi$ characterized by $\phi(k)=0$ iff $k=k$ provided $\sigma_{F} \geqslant 1$, while in unemployment capital accumulates according to $\dot{k}=\phi\left(k^{\mathrm{d}}(w)\right) k$.
} 


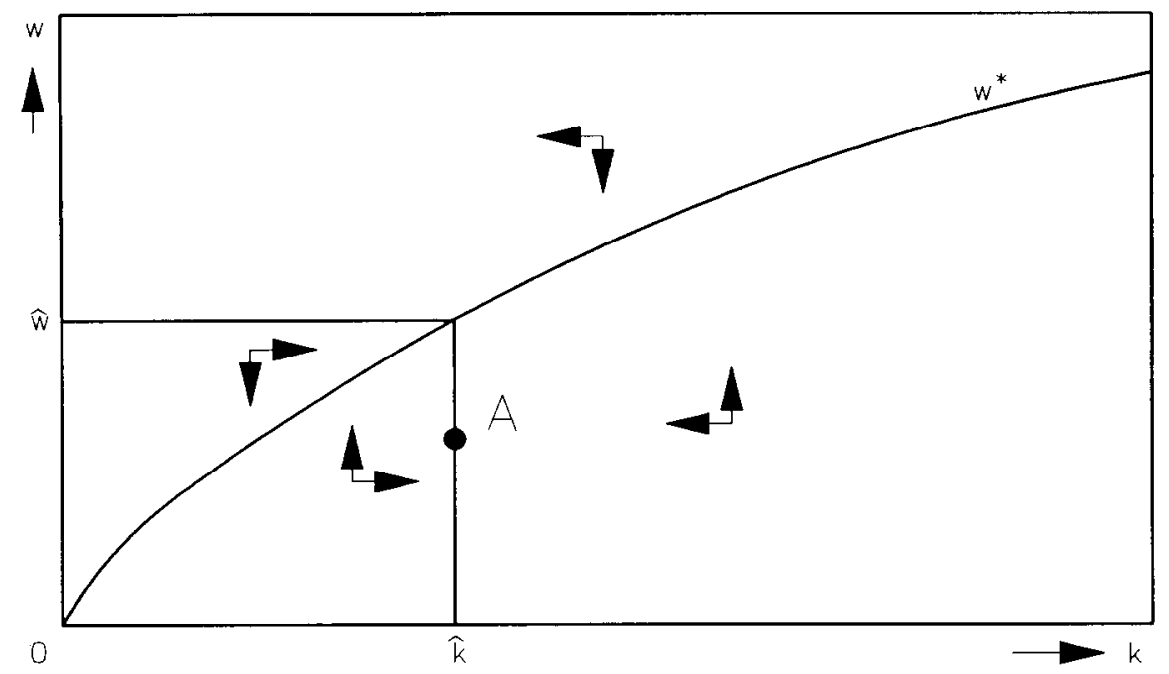

Fig. 1. Dynamic behavior in the benchmark case: Laborers receive the profits and rationing is efficient.

tion, the sequel of the paper will investigate the various possibilities in this respect.

\section{Profit distribution and efficient rationing}

If rationing is efficient labor is allocated such as to equalize the VMPL in the two sectors, and hence profits per worker. Eq. (3) becomes

$$
w<f_{1}-k_{1} f_{1}^{\prime}=p\left\{f_{2}-k_{2} f_{2}^{\prime}\right\} .
$$

First, we discuss profit distribution and, second, we examine stability.

\subsection{Laborers receive the profits (the benchmark case)}

Due to efficient rationing the VMPL is the same in both sectors and both sectors make a profit, hence $l_{n}=1$. Distributing profits to the laborers, $s_{n}=s_{w}$, amounts to a roundabout way of paying them their $V M P L$. Hence Eq. (2) reduces to Eq. (2), which implies that production in both sectors is equal to the production level at full employment (given $k$ ). Therefore, capital accumulates (decumulates) iff $k$ is smaller (larger) than $\hat{k}$, which gives the following proposition (illustrated in Fig. 1): 
Proposition 2. If laborers receive the profits and rationing is efficient the short-run excess-demand equilibrium exists and is unique if $\sigma_{1}+\sigma_{2} \geqslant 1$. The state variables evolve according to $w>0$ and $\dot{k} \leqq 0$ iff $k \lesseqgtr k$, provided $\sigma_{F} \geqslant 1$.

Ito (1980) implicitly assumes that capital-owners receive the profits. $\mathrm{He}$ then derives that the $\dot{k}=0$ locus is vertical in the excess-demand regime iff laborcrs and capital-owners have identical saving behavior $\left(s_{r}=s_{w}\right)$. The same holds in the two-sector model if rationing is efficient (see below). However, Proposition 2 shows that it is more important to determine who gets the profits, because the $\dot{k}=0$ locus is always vertical in the excess-demand regime if profits go to the laborers (even if $s_{r} \neq s_{w}$ ).

\subsection{Capital-owners receive the profits}

Proposition 3. If capital-owners receive the profits and rationing is efficient the short-run excess-demand equilibrium exists and is unique. The $\dot{k}=0$ locus is given by the function $w=\phi(k)$ if $s_{w} \neq s_{r}$ and vertical at $\hat{k}$ otherwise. The state variables evolve according to $\dot{w}>0$ and for the domain of $\phi$,

$$
\begin{array}{lll}
\dot{k} \gtreqless 0 & \text { iff } \quad w \gtreqless \phi(k) \text { for } s_{w}>s_{r}, \quad \text { and } \\
\dot{k} \gtreqless 0 & \text { iff } \quad w \gtreqless \phi(k) \text { for } s_{w}<s_{r} .
\end{array}
$$

Proposition 3 , which follows from putting $l_{\pi}=1$ and $s_{\pi}=s_{r}$ in $\left(2^{\prime}\right)$, implies that $\phi$ is upward sloping if capital-owners save less than laborers (Fig. 2a) and downward sloping otherwise (Fig. 2b) and can be understood quite easily. If the saving behavior of the capital-owners is identical to the laborer's saving behavior $\left(s_{r}=s_{w}\right)$, then the economy behaves again as at full employment. Starting, however, from a point in the excess-demand regime where $k=\hat{k}$ (like point $\mathrm{A}$ in Fig. 1), combined with capital-owners, who save more than laborers $\left(s_{r}>s_{w}\right)$, the demand for investment goods must increase $\left(y_{1}\right.$ increases) while depreciation and population growth do not change $((\delta+n) \hat{k}$ remains the same) hence capital must still accumulate $\left(\dot{k}=y_{1}-(\delta+n) \hat{k}>0\right)$. This explains the downward slope of $\phi$ if $s_{r}>s_{w}$. The same holds, mutatis mutandis, for $s_{r}<s_{w}$. The basic results are summarized in Table 1 .

\section{Stability}

The 'usual' analysis for stability of a system of differential equations cannot be applied here without restrictions and modifications. This is caused by the fact that the system consists of two different sets of differential equations with the possibility of switching regimes. Define $R_{U} \equiv\left\{(k, w) \in R_{+}^{2} \mid\right.$ $\left.w>w^{*}(k)\right\}$ and $R_{E} \equiv\left\{(k, w) \in R_{+}^{2} \mid w<w^{*}(k)\right\}$, then the dynamic behavior of the model is given by 

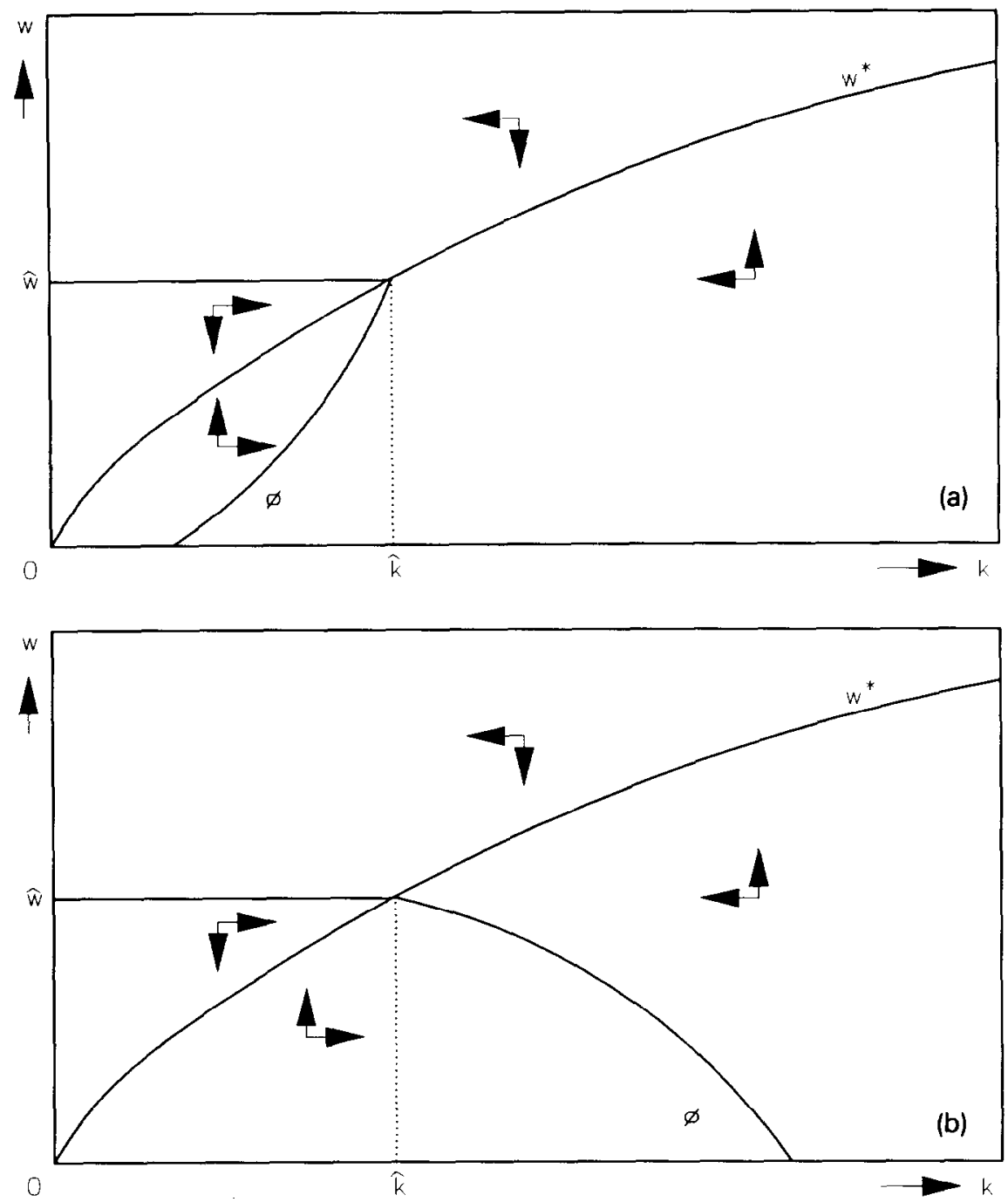

Fig. 2. Dynamic behavior if rationing is efficient: capital-owners receive the profits and (Fig. 2a) save less than the laborers or (Fig. 2b) save more than the laborers.

$$
\left(\begin{array}{c}
\dot{k} \\
\dot{w}
\end{array}\right)=\left(\begin{array}{cccc}
\psi_{j}(k, w) \\
\theta_{j}(k, w)
\end{array}\right) \quad \begin{array}{lll}
j=U & \text { if } & (k, w) \in R_{U} \\
j=E & \text { if } & (k, w) \in R_{E}
\end{array}
$$

With a discontinuity on the common boundary of Lebesgue-measure zero $w=w^{*}(k)$. The Filippov solution ignores vectors of direction on an arbitrary set of Lebesgue-measure zero near a point of discontinuity. It is possible that the 'patched up' system is unstable although the two systems themselves are 
Table 1

Behavior in excess-demand if rationing is efficient; the $\dot{k}=0$ locus is given by $w=\phi(k)$

\begin{tabular}{|c|c|c|}
\hline & $w$ & $k$ \\
\hline \multicolumn{3}{|c|}{ (i) Laborers receive the profits $\left(\sigma_{1}+\sigma_{2} \geqslant 1\right)$} \\
\hline$k_{1}$ & 0 & + \\
\hline$k_{2}$ & 0 & + \\
\hline$l_{1}$ & 0 & $?$ \\
\hline \multicolumn{3}{|c|}{$\phi^{\prime}=\infty$} \\
\hline \multicolumn{3}{|c|}{ (ii) Capital-owners receive the profits } \\
\hline$k_{1}$ & + iff $\left(s_{w}-s_{v}\right)\left(k_{1}-k_{2}\right)<0$ & + \\
\hline$k_{2}$ & + iff $\left(s_{w}-s_{r}\right)\left(k_{1}-k_{2}\right)<0$ & + \\
\hline$l_{1}$ & $+\operatorname{iff}\left(s_{w}-s_{r}\right)>0$ & $?$ \\
\hline \multicolumn{3}{|c|}{$\phi^{\prime}>0$ if $s_{r}<s_{w}, \sigma_{E}, \sigma_{F} \geqslant 1$} \\
\hline & ${ }_{w}, \sigma_{F} \geqslant 1, \hat{\sigma}_{E} \geqslant s_{r} / s_{w}$ & \\
\hline
\end{tabular}

stable. It is clear from Figs. 1 and 2, however, that if $s_{\pi}=s_{w}$ or $s_{\pi}=s_{r}$ and $s_{r} \leqslant s_{w}$ the system is globally stable if it arrives in the excess-demand regime without complete decapitalization. This is caused by the solution path getting 'locked in' between $w^{*}(k)$ and $\phi(k)$ and approaching the long-run equilibrium point $(\hat{k}, \hat{w})$ asymptotically. Let $\sigma_{E}$ be the overall elasticity of substitution in the excess-demand regime and $\hat{\sigma}_{E}$ be $\sigma_{E}$ evaluated at the steady state, then

Proposition 4. With efficient rationing the system is globally asymptotically stable if

(i) laborers receive the profits and $\sigma_{F} \geqslant 1$ or

(ii) capital-owners receive the profits and do not save more than laborers $\left(s_{r} \leqslant s_{w}\right)$ together with $\sigma_{E}, \sigma_{F} \geqslant 1$.

If $\phi$ is downward sloping $\left(s_{\pi}=s_{r} \wedge s_{w}<s_{r}\right)$ it is not apparent that the system is stable. We can, however, get a local result.

Proposition 5. With efficient rationing the system is locally asymptotically stable if capital-owners receive the profits and save more than laborers together with

(i) $k_{1} \leqslant k_{2}$ and $\sigma_{F} \geqslant 1$ or

(ii) $k_{1}>k_{2}, \sigma_{F} \geqslant 1$ and $\hat{\sigma}_{E}>\left(k_{1}-k\right) s_{r} / s_{w}\left(k_{1}+\omega\right)$.

The proof uses the fact that the individual dynamic systems are stable while it is clear that we cross the boundary if it is reached. Honkapohja and Ito (1983) show that under these conditions local stability holds. Note that $\sigma_{F} \geqslant 1$ and $\hat{\sigma}_{E} \geqslant s_{r} / s_{w}$ are always sufficient conditions for local stability in the case described in Proposition 5. 


\section{Sector specific rationing}

This section briefly discusses the properties of a sector specific rationing scheme, which will be evaluated at the steady state. Suppose that, due to political pressure or otherwise, one sector will not be rationed if the economy is in excess-demand. The 'privileged' sector (the one that is not rationed) can fulfill its demand for labor at the current wage rate. Hence it is not making a profit (privileges have their drawbacks).

\subsection{The investment good industry is not rationed}

Suppose the investment good industry is not rationed. Then the wage rate equals the value marginal product of labor in the investment good sector, $w=V M P L_{1}=f_{1}-k_{1} f_{1}^{\prime}$ which gives $k_{1}$ as a function of $w$. Naturally, the consumption good industry makes a profit, $w<p\left(f_{2}-k_{2} f_{2}^{\prime}\right)$.

\subsubsection{Laborers receive the profits}

If the laborers receive the profits made in the consumption good sector we get $s_{\pi}=s_{w}, V M P L_{\pi}=V M P L_{2}$ and $l_{\pi}=l_{2}$ in investment equation (2'). Look at point $\mathrm{A}$ in Fig. 1. If rationing were efficient (so the production of both goods would be rationed) $\dot{k}$ would be zero at this point. Now, however, the production of investment goods is not rationed, hence its production increases. Depreciation and population growth do not change $((\delta+n) \hat{k}$ remains the same), hence capital must accumulate at point $A$ $\left(\dot{k}=y_{1}-(\delta+n) \hat{k}>0\right)$. Therefore the $\dot{k}=0$ locus is downward sloping in the excess-demand regime if the investment good industry is not rationed and laborers receive the profits (Fig. 2b). Alternatively, one can distinguish between two effects and argue as follows. At point $\mathrm{A}$ the wage rate is lower than $\hat{w}$, hence the capital-labor ratio in sector 1 is lower. Given $l_{1}$ this tends to decrease $y_{1}\left(=l_{1} f_{1}\left(k_{1}\right)\right)$. Producers in industry 1 , however, are not rationed and can attract more laborers, which will increase $l_{1}$. Given $k_{1}$ this will tend to increase $y_{1}$. As in excess-demand labor is the constraining factor the labor effect will dominate the capital intensity effect.

\subsubsection{Capital-owners receive the profits}

If the capital-owners receive the profits made in the consumption good sector we get $s_{\pi}=s_{r}, V M P L_{\pi}=V M P L_{2}$ and $l_{\pi}=l_{2}$ in investment equation (2'). Again look at point A in Fig. 1. Two (possibly opposing) forces are at work at this point. First, rationing the consumption good market will increase the production of investment goods. Second, distributing part of the GNP to the capital-owners will increase the demand for investment goods only if they save more out of these profits. Hence the $\dot{k}=0$ locus will be downward 
Table 2

Behavior in excess-demand if investment goods are not rationed; the $\dot{k}=0$ locus is given by $w=\phi(k)$

$w$

(i) Laborers receive the profits $\left(\sigma_{2} \geqslant s_{w}\right)$.

$\begin{array}{ll}k_{1} \quad+ & 0 \\ k_{2} \quad-\left(\sigma_{1} \geqslant 1-s_{w}\right) & + \\ \mathrm{l}_{1} \quad- & + \\ \phi^{\prime}<0 \text { if } \sigma_{2} \geqslant 1 & \end{array}$

(ii) Capital-owners receive the profits $\left(\sigma_{2} \geqslant s_{\text {r }}\right)$.

\begin{tabular}{lll}
$k_{1}$ & + & 0 \\
$k_{2}$ & $?$ & + \\
$l_{1}$ & - & + \\
$\phi^{\prime}<0$ if $s_{r}\left(1-l_{1}\right)>s_{w}$, & $\sigma_{2} \geqslant s_{r} / s_{w}$ & \\
\hline
\end{tabular}

sloping if $s_{r} l_{2} \geqslant s_{w}$. If, on the other hand, capital-owners save less out of profits than laborers we have two opposing forces at work. The rationing scheme tends to increase the production of investment goods, while profit distribution to the capital-owners tends to decrease the demand for these goods. The slope of the $\dot{k}=0$ locus cannot be determined without further information on the production functions and the size of the two savings rates. The qualifications and restrictions needed to derive the conclusions intuitively explained in this section are listed in Table 2.

\subsection{The consumption good industry is not rationed}

If the consumption good industry is not rationed the wage rate equals the value marginal product of labor in the consumption good sector, $w=$ $V M P L_{2}=p\left(f_{2}-k_{2} f_{2}^{\prime}\right)$. This time the investment good industry makes a profit $\left(l_{\pi}=l_{1}\right.$ and $\left.w<f_{1}-k_{1} f_{1}^{\prime}\right)$. If laborers receive the profits the production of investment goods at point A in Fig. 1 decreases, so capital is decumulating at that point. Therefore the $\dot{k}=0$ locus must be upward sloping in the excessdemand regime, as in Fig. 2a. If capital-owners receive the profits we are again confronted with two (possibly opposing) forces. Rationing the investment good industry tends to decrease production in this sector. This effect is reinforced from the demand side if profits are distributed to the capitalowners and they save less out of these profits than laborers $\left(s_{r} l_{1} \leqslant s_{w}\right)$. Under this condition, then, the $\dot{k}=0$ locus will be upward sloping (Fig. 2a). Otherwise (if capital-owners save more out of profits than laborers) the demand for investment goods will increase, a force that can potentially 
Table 3

Behavior in excess-demand if consumption goods are not rationed; the $\dot{k}=0$ locus is given by $w=\phi(k)$

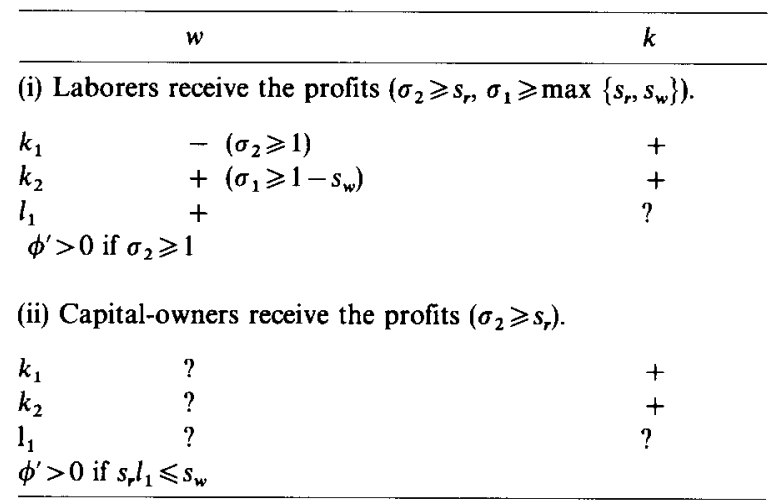

counterbalance the rationing effect. Table 3 summarizes the conclusions and gives qualifications.

\section{Government consumption}

Introducing a government sector in the benchmark model enables us to analyze the effect of changes in government consumption on the disequilibrium growth path and the pressure in the labor market. The role of the government is limited. Tax revenues are used to buy consumption goods, $\tau\left(y_{1}+p y_{2}\right)=g$, where $g$ is government consumption and $\tau$ is the tax rate to finance this consumption. Equilibrium in the investment good industry for the benchmark case becomes $\left(y_{1}=(1-\tau)\left(s_{w} w+s_{r} r k\right)=s_{w} w+s_{r} r k-g\right)$

$$
l_{1} f_{1}-s_{w}\left(f_{1}-k_{1} f_{1}^{\prime}\right)-s_{r} k f^{\prime}{ }_{1}+g=0 .
$$

The balanced budget multipliers for each regime are easily calculated and summarized in Table 4. Naturally, an increase in government consumption will reduce the steady-state capital-labor ratio. Moreover, in the fullemployment short-run it will pull laborers away from the investment good industry toward the consumption good industry. If the investment good industry is relatively capital intensive $\left(k_{1}>k_{2}\right)$, the consumption good sector will need relatively more laborers than capital to produce the extra demand for consumption goods, hence $k_{1}$ and $w^{*}$ will rise and $k_{2}$ will fall. In the unemployment regime changes in $g$ are completely absorbed by changes in the overall demanded capital-labor ratio $\left(k^{\mathrm{d}}\right)$ and the fractions of labor demanded in each sector $\left(l_{1}^{\mathrm{d}}\right.$ and $\left.l_{2}^{\mathrm{d}}\right)$. Suppose we are at point B in Fig. 3, 
Table 4

Effects of an increase in government consumption (benchmark case)

\begin{tabular}{llll}
\hline & Full employment & Unemployment & Excess-demand \\
\hline$k$ & - & & \\
$w^{*}$ & + iff $k_{1}>k_{2}$ & & + iff $k_{1}>k_{2}$ \\
$k_{1}$ & + iff $k_{1}>k_{2}$ & 0 & + iff $k_{1}>k_{2}$ \\
$k_{2}$ & - iff $k_{1}>k_{2}$ & 0 & - \\
$l_{1}$ & - & - & - iff $k_{1}>k_{2}$ \\
$k^{\mathbf{d}}$ & & - iff $k_{1}>k_{2}$ & - \\
$y_{1}$ & - & - & \\
\hline
\end{tabular}

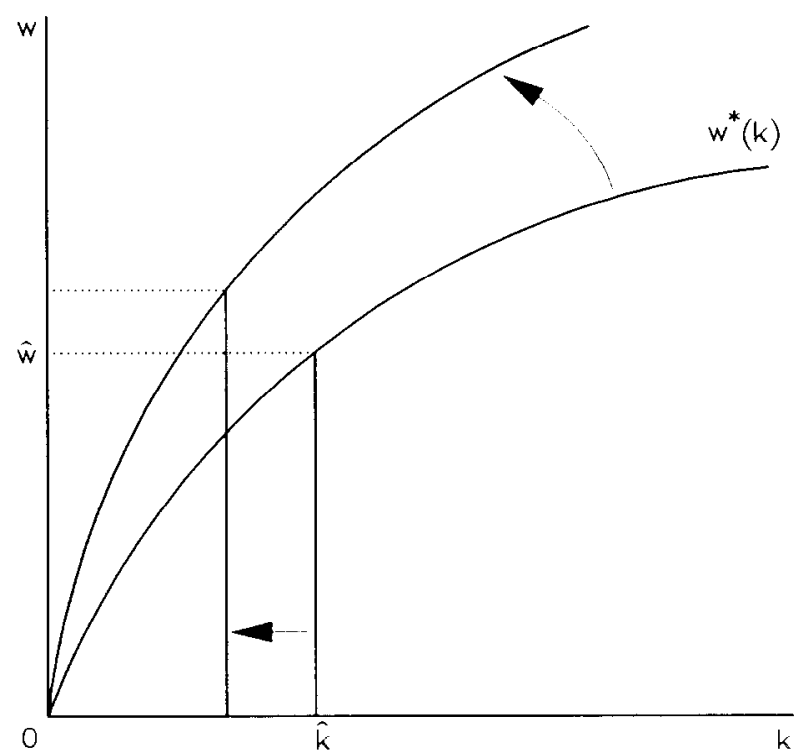

Fig. 3. The effect of an increase in government consumption if the investment good industry is relatively capital intensive.

where part of the labor force is unemployed. Conventional wisdom has it that the government should increase its consumption to create extra demand and employ more laborers ( $g$ increases). If $k_{1}>k_{2}$ this rotates the $w^{*}(k)$ locus counterclockwise up and reduces $k^{\mathrm{d}}$, hence indeed reduces the pressure in the labor market. If $k_{1}<k_{2}$, however, the $w^{*}(k)$ locus rotates clockwise down, $k^{\text {d }}$ increases and the pressure on the labor market increases. Therefore, an increase in government consumption in unemployment is only a wise policy 
if the investment good industry is relatively capital intensive. This is intuitively plausible because the wage rate fixes $k_{1}^{\mathrm{d}}$ and $k_{2}^{\mathrm{d}}$, whereas the increase in $g$ increases demand for consumption goods and hence pulls laborers to this sector. Total labor employed will only increase if sector 2 uses these laborers relatively more intensively $\left(k_{2}<k_{1}\right)$. Similar arguments, necessary changes being made, hold for the excess-demand regime. It is important to note that these observations do not depend on a specific rationing scheme as it is only the $w^{*}(k)$ locus relative to the $(k, w)$ point under investigation that matters, which in turn depends only on $k_{1}-k_{2}$. In concluding, the effects of discretionary government policy depend crucially on the relative capital intensities?

\section{Conclusion}

We investigate a two-sector disequilibrium growth model with sluggish real wage rate adjustment. There is an explicit analysis of spill-over effects in a general (dis)equilibrium framework and simultaneous adjustment of prices and quantities in the long run as a sequence of short-run fixed price equilibria. We derive various global and local stability results by making sufficiently strong assumptions on the elasticities of substitution.

Introduction of a second output sector makes the model more 'Keynesian', in the sense that more attention must be given to the rationing problem. We analyze both efficient rationing and sector-specific rationing. The difference in the rationing scheme used shows up exclusively in the excess-demand regime. Moreover, we note that in the excess-demand regime (where profits are being made) it is of significant importance to decide who gets these profits. There are two powers operative in excess-demand: profit distribution and the rationing scheme. Sometimes these powers will reinforce each other (for example if the investment good industry is not rationed, while profits go to the capital-owners who save more than laborers), sometimes they will contradict (idem if capital-owners save less).

Extending the model with a government sector shows that an increase in government consumption in unemployment (excess demand) is only beneficial for the economy, i.e. will reduce pressure on the labor market, if and only if the investment good (consumption good) industry is relatively capital intensive. It is, therefore, of crucial importance for the government to know which industry is relatively capital intensive to achieve the desired result. The power of the government in a two-sector model is therefore much greater than in the Ito (1980) one-sector model because it cannot only influence the

\footnotetext{
${ }^{7}$ Government investment leads to similar conclusions, depending on the use of the investment goods.
} 
long-run steady state and the dynamic path to it, but also alleviate short-run pressure on the labor market, i.e. 'fine tune' the economy, provided it has enough information on the workings of the economy. Naturally, the twosector distinction must be non-trivial, i.e. the two sectors must be different and have different capital-labor ratios. Otherwise, the government is powerless in the short run.

\section{References}

Barro, R.J. and H.I. Grossman, 1971, A general disequilibrium model of income and unemployment, American Economic Review 61, 82-93.

Benassy, J.-P., 1982, The economics of market disequilibrium (Academic Press, New York).

Blinder, A.S., 1991, Why are prices sticky? Preliminary results from an interview study, American Economic Review 81, 89-96.

Cooper, R. and A. John, 1988, Coordinating coordination failures in Keynesian models, Quarterly Journal of Economics 103, 441-463.

Drandakis, E., 1963, Factor substitution in the two-sector growth model, Review of Economic Studies 38, 217-228.

Eckwert, B. and U.K. Schittko, 1988, Disequilibrium dynamics, Scandinavian Journal of Economics 90, 189-209.

Filippov, A.F., 1960, Differential equations with discontinuous right-hand side, Matematicheskii Sbornik 51, 99-128.

Ginsburgh, V., P.Y. Henin and Ph. Michel, 1985, A dual decision approach to disequilibrium growth, Oxford Economic Papers 37, 353-361.

Honkapohja, S. and T. Ito, 1982, Disequilibrium dynamics with monetarist price expectations, Economics Letters 9, 69-75.

Honkapohja, S. and T. Ito, 1983, Stability with regime switching, Journal of Economic Theory $29,22-48$.

Ito, T., 1980, Disequilibrium growth theory, Journal of Economic Theory 23, 380-409.

Picard, P., 1983, Inflation and growth in a disequilibrium macroeconomic model, Journal of Economic Theory 30, 266-295.

Romer, P., 1986, Increasing returns and long run growth, Journal of Political Economy 94, 1002-1037.

Schittko, U.K. and B. Eckwert, 1985, Dynamic aspects in a temporary equilibrium model of international trade with quantity rationing, European Journal of Political Economy 1, 189-220.

Solow, R.M., 1956, A contribution to the theory of economic growth, Quarterly Journal of Economics 70, 65-94.

van Marrewijk, C. and J. Verbeek, 1993a, Disequilibrium growth theory in an international perspective, Oxford Economic Papers 45, 311-331.

van Marrewijk, C. and J. Verbeek, 1993b, Sector specific capital, 'bang-bang' investment and the Filippov solution, Journal of Economics 57, 131-146.

Verbeek, J., 1993, Studies in economic growth theory, Ph.D. Dissertation, Erasmus University Rotterdam. 